\title{
FEIRAS DE CIÊNCIAS: O QUE EMERGE SOBRE CONTROVÉRSIAS SOCIOCIENTÍFICAS E INTERDISCIPLINARIDADE NESSE ESPAÇO NÃO FORMAL DE EDUCAÇÃO? ${ }^{1}$
}

\author{
SCIENCE FAIR: WHAT EMERGES ABOUT SOCIOSCIENTIFIC CONTROVERSIES \\ AND INTERDISCIPLINARITY IN THIS NON-FORMAL EDUCATION AREA?
}

\author{
ARAUJO, Rafaele Rodrigues de ${ }^{2}$ \\ HAUSCHILD, Mailin Elisabeth ${ }^{3}$
}

\begin{abstract}
RESUMO
O objetivo do trabalho foi investigar como o espaço não formal de uma Feira de Ciências possibilita a emergência de temáticas voltadas às controvérsias sociocientíficas, na perspectiva interdisciplinar. A pesquisa se caracteriza por ser de cunho qualitativo, documental e interdisciplinar, sendo que ocorreu por meio da análise dos resumos publicados por estudantes da Educação Básica na terceira edição do projeto de extensão Feira de Ciências: Integrando Saberes no Cordão Litorâneo. Com o processo da análise documental realizada, encontramos duas categorias iniciais que dissertam sobre as relações das controvérsias sociocientíficas e os temas voltados ao comportamento humano e o meio ambiente, os quais emergem na Feira de Ciências e possibilitam reflexões, interações e o desenvolvimento de tecnologias. Com isso argumentamos que o espaço da Feira de Ciências promove a auto-eco-formação dos estudantes, por meio da interação entre os pares, com os professores e o meio ambiente.
\end{abstract}

Palavras-chave: Controvérsias Sociocientíficas; Feira de Ciências; Interdisciplinaridade; Auto-ecoformação; Extensão.

\section{ABSTRACT}

The aim of the work was to investigate how the non-formal space of a Science Fair enabled the emergence of themes related to socioscientific controversies, from an interdisciplinary perspective. The research is characterized by being of qualitative, documentary and interdisciplinary nature, and it occurred through the analysis of the abstracts published by students of Basic Education in the third edition of the extension project "Feira de Ciências: Integrando Saberes no Cordão Litorâneo" ou "Science Fair: Integrating Knowledge in the Coastal Cordon" With the documental

\footnotetext{
1 Apoio do Conselho Nacional de Desenvolvimento Científico e Tecnológico - CNPq.

2 Universidade Federal do Rio Grande - FURG / Instituto de Matemática, Estatística e Física. Rio Grande, RS, Brasil. ORCID: https://orcid.org/0000-0003-4901-6196 e-mail: araujo.r.rafa@gmail.com

3 Universidade Federal do Rio Grande - FURG / Instituto de Matemática, Estatística e Física. Rio Grande, RS, Brasil. ORCID: https://orcid.org/0000-0002-5744-4062 e-mail: mailinhauschild@gmail.com
} 
DOI: $10.12957 /$ e-mosaicos.2021.49821

analysis process performed, we found two initial categories that talk about the relations of socioscientific controversies and themes related to human behavior and the environment, which emerge at the Science Fair and enabled for reflections, interactions and the development of technologies. With that, we argue that the Science Fair space promotes students' self-eco-training, through interaction between peers, teachers and the environment.

KEY WORDS: Socioscientific controversies; Science fair; Interdisciplinarity; Self-eco-training; Extension.

\section{CONSIDERAÇÕES INICIAIS}

As temáticas das controvérsias sociocientíficas (CSC), assim como a interdisciplinaridade, apresentam uma série de definições e de perspectivas dentro do contexto da Educação. Perceber como essas podem estar articuladas é um desafio que se faz presente, mas que, se analisarmos com um olhar em que diminua as fronteiras das áreas do conhecimento, se torna mais fácil de compreender suas correlações.

Ressaltamos que as controvérsias sociocientíficas (CSC) possuem uma diversidade de definições, sendo caracterizadas, segundo Reis (2003), por discussões que partem do impacto social de inovações científicas e tecnológicas que dividem a comunidade científica e a sociedade em geral, e para as quais diferentes grupos de cidadãos propõem explicações e tentativas de resolução incompatíveis, baseadas em valores alternativos. Com isso, essas controvérsias trazem à tona discussões, às quais duas ou mais partes debatem com base em suas crenças e suas argumentações, porém os resultados não podem ser definidos apenas por meio da análise das evidências ou das experiências.

As CSC estão muito associadas à perspectiva Ciência, Tecnologia, Sociedade e Ambiente (CTSA) em que temos a articulação desses importantes conceitos dentro de cada área do saber. Conforme Galvão, Reis e Freire (2011) explicitam, a maioria das organizações curriculares que envolvem CTSA apresentam objetivos que vão desde 0 aumento e propagação da literacia científica pelos cidadãos, o despertar do interesse pelos estudantes em relação à ciência e à tecnologia, o estímulo pelas interações entre os pilares do enfoque CTSA e o desenvolvimento do pensamento crítico e reflexivo na tomada de decisões. Além disso, de acordo com Ramos e Silva $(2007$, p. 5)

[...] alguns estudos de caso provenientes dos estudos de controvérsia podem ser importantes, se conduzidos à sala de aula: demonstrando o quão efêmeras, mutáveis, incompletas podem ser as certezas dos conhecimentos científicos (como todas as outras certezas) e que, de qualquer forma, influenciarão de maneira significativa o modo como 
DOI: $10.12957 /$ e-mosaicos.2021.49821

julgaremos todos estes conhecimentos na hora de definir nossas ações perante a vida. (RAMOS e SILVA, 2007, p. 5)

Com isso, trabalhar de maneira interdisciplinar ou de modo a deixar florescer os diversos conceitos presentes nas temáticas que contribuem para as discussões científicas se torna imprescindível. Nessa perspectiva, percebemos que a interdisciplinaridade se faz presente na discussão das CSC, visto que muitas das temáticas que são emergentes abrangem diversas áreas do conhecimento. Dessa forma, ser uma pessoa que busca a interdisciplinaridade no seu modo de ser e agir se torna importante nesse contexto, ainda mais quando se trata do âmbito educacional. Ressaltamos que a prática de um professor interdisciplinar em sala de aula possibilitará o surgimento de questões voltadas às CSC.

Entendemos por um professor interdisciplinar aquele que apresenta alguns princípios como humildade, coerência, desapego, respeito e espera (FAZENDA, 2006). Esses princípios contribuirão para uma prática interdisciplinar em sala de aula, visto que a mesma exige humildade para compreender que seu conhecimento não é único e nem o suficiente; coerência com o que falamos e fazemos; desapego de nossas ideias, bens físicos e /ou materiais, de modo a abrir espaço ao surgimento de novos entendimentos; respeito consigo e com os outros e espera de conseguir observar no espaçotempo de cada sujeito, de modo a conseguir refletir e agir de maneira mais adequada (FAZENDA, TAVARES e GODOY, 2015).

Além disso, competências são necessárias a esse docente que busca uma prática interdisciplinar, como uma competência intuitiva, intelectiva, prática e emocional. De acordo com Fazenda, Tavares e Godoy (2015) as competências vão desde a capacidade de ousar, buscar alternativas novas e diferenciadas, refletir, questionar, se organizar em relação ao espaçotempo e se autoconhecer para buscar o conhecimento. Nesse sentido, emergem questionamentos: Como um professor interdisciplinar tem práticas em sala de aula que possibilitam a discussão de temas sociocientíficos? Um professor que apresenta princípios e competências interdisciplinares na sua forma de ser e agir, tem uma abertura maior para a discussão de temas controversos da Ciência? Galvão, Reis e Freire (2011) afirmam que não adianta somente alterações nos currículos para termos discussões sobre as controvérsias científicas em sala de aula, mas sim um investimento na formação de professores, que ocorre ainda muito embasada em uma ciência neutra, transmissiva, sem dar ênfase na construção do conhecimento científico.

Apesar dessas questões elencadas, temos espaços não formais na Educação que possibilitam a emergência e a discussão das CSC, como as Feiras de Ciências. De acordo com Reis (2004), esses espaços promovem a educação científica, sendo de natureza econômica, utilitária, cultural, democrática e moral. Sendo assim, em muitos países houve 
DOI: $10.12957 / \mathrm{e}-\mathrm{mosaicos} .2021 .49821$

um movimento de revitalização dos museus, o aumento do espaço destinado à ciência nos meios de comunicação e a organização de grandes exposições e feiras de ciência.

Mancuso e Leite Filho (2006) definem as Feiras de Ciências como eventos sociais, científicos e culturais, que oportunizam, além do diálogo com os visitantes, a problematização de conhecimentos, metodologias de pesquisa e instigam a criatividade dos estudantes em todos os sentidos. Com isso, as Feiras de Ciências se tornaram um dos espaços nos meios de ensino de incentivar e de instigar novos cientistas, que sejam críticos e que saibam buscar informações para a resolução dos problemas, além de possibilitar o repensar de novas tecnologias.

Nesse sentido, no trabalho, investigamos como o espaço não formal de uma Feira de Ciências possibilita a emergência de temáticas voltadas às controvérsias sociocientíficas na perspectiva interdisciplinar. Para isso, nosso olhar foi sobre a terceira edição do projeto de extensão "Feira de Ciências: Integrando Saberes no Cordão Litorâneo", a qual realiza uma Feira de Ciências no município de Rio Grande/RS em parceria com a Universidade Federal do Rio Grande - FURG.

O projeto de extensão tem três etapas em que uma delas é a formação continuada de professores que realizarão as Feiras de Ciências nas escolas e que nesse curso discutem temas como projetos investigativos e a interdisciplinaridade. Sendo assim, algumas questões norteiam a pesquisa documental que realizamos: Como os professores participantes do processo de formação do projeto de extensão, por meio da interdisciplinaridade, adentram nas CSC em uma Feira de Ciências? Como isso reflete nos trabalhos apresentados pelos estudantes? Essas perguntas que nos movimentaram a investigar quais as temáticas presentes em resumos de trabalhos apresentados por estudantes da Educação Básica, em uma Feira de Ciências investigativa e interdisciplinar referentes às controvérsias sociocientíficas, e, como essas discussões podem contribuir para suas formações.

\section{Caminho Metodológico}

A pesquisa realizada apresenta cunho qualitativo, documental e interdisciplinar. Consideramos a pesquisa interdisciplinar visto que, segundo Bicudo (2008, p. 145, grifo nosso), "[...] a interdisciplinaridade é um modo de proceder, de pesquisar. Em si, não é uma ontologia e também não é uma epistemologia. Ao contrário, ela repousa sobre concepções ontológicas e epistemológicas específicas". Além disso, a interdisciplinaridade vai além de uma simples articulação ou integração de disciplinas, consistindo em um modo de ser, de agir e de pensar. Operamos com as diversas competências e princípios de um professor pesquisador interdisciplinar, seja na forma de buscarmos ou olharmos de forma atenta para nossas informações. Nesse sentido, a pesquisa pode ser descrita como qualitativa por enfatizar a 
DOI: $10.12957 /$ e-mosaicos.2021.49821

[...] necessidade do exercício da competência e da imaginação pelo pesquisador, num tipo de trabalho artesanal, não só como condição para o aprofundamento da análise, mas para a liberdade intelectual. O importante é produzir um conhecimento que, além de útil, seja orientado por um projeto ético visando ao crescimento, à autonomia e à criatividade (FAZENDA, TAVARES e GODOY, 2015, p. 62).

Além disso, Galeffi (2009, p. 13-14) reforça que toda pesquisa qualitativa deseja "[...] realizar o processo de desenvolvimento do conhecimento humano em sua dinâmica gerativa e em sua organização vital, em sua natureza histórica e existencial, e em seu modo de comportamento conjuntural e complexo". Para isso, realizamos uma análise documental dos resumos publicados dos trabalhos apresentados por estudantes que participaram da terceira edição do projeto de extensão da Feira de Ciências: Integrando Saberes no Cordão Litorâneo.

Segundo Kripka, Scheller e Bonotto (2015), a pesquisa documental é um processo de compreensão da realidade social e de produção de conhecimento, a partir de diferentes documentos que, ainda, não foram analisados e sistematizados, ou que possam ser reexaminados. Sendo assim, é muito importante, neste processo, a capacidade do pesquisador de selecionar e de interpretar a informação, criando novos conhecimentos, reavaliando compreensões anteriores dos fenômenos e buscando conhecer o desenvolvimento destes (SÁ-SILVA; ALMEIDA; GUINDANI, 2009, p. 14). Nessa perspectiva, a pesquisa e a análise documental serve de base para o debate qualitativo das informações.

Dessa forma, nos próximos tópicos, apresentaremos o projeto de extensão e as etapas que permeiam o mesmo, devido ser o campo da pesquisa realizada a análise dos resumos publicados pelos estudantes e a discussão das categorias emergentes.

\section{O PROJETO de EXTENSÃo E O CURSO dE FORMAÇÃo PARA PROFESSORES}

O projeto de extensão "Feira de Ciências: Integrando Saberes no Cordão Litorâneo" é um dos projetos desenvolvidos por docentes do Instituto de Matemática, Estatística e Física (IMEF) da Universidade Federal do Rio Grande - FURG e que tem por finalidade promover a formação inicial e continuada de professores, assim como instigar estudantes da Educação Básica a querer seguir carreiras científicas. Sendo assim, o referido projeto emerge da necessidade de resgatar as Feiras de Ciências nas escolas, visando a contribuir no desenvolvimento científico, tecnológico e na inovação, tal como estimular o debate com temas científicos, o incentivo á alfabetização científica e da interdisciplinaridade na Educação Básica, com aposta no processo formativo de professores. O projeto é desenvolvido desde 2015 por docentes do IMEF, grupo de 
DOI: $10.12957 / \mathrm{e}-\mathrm{mosaicos} .2021 .49821$

pesquisa Comunidade de Indagação em Ensino de Física Interdisciplinar (CIEFI), mestrandos e doutorandos do Programa de Pós-Graduação em Educação em Ciências PPGEC, professores colaboradores da rede de ensino e acadêmicos do curso de licenciatura em Física da Universidade Federal do Rio Grande - FURG.

Compreendemos que o espaço não formal da Feira de Ciências se torna um momento em que é possível envolver o aluno em uma investigação científica, propiciando um conjunto de experiências interdisciplinares, além de abranger o repensar da prática do corpo docente em atividades diferenciadas e integradas. Mancuso e Leite Filho (2006) explicitam que as Mostras e Feiras de Ciências se constituem por um espaço que possibilita a discussão sobre os saberes, as metodologias de pesquisa e possibilita a criatividade dos estudantes em todos os aspectos referentes à exibição dos trabalhos. Nesse sentido, o espaço das Feiras de Ciências se torna um potencial no surgimento de trabalhos que discutam as controvérsias sociocientíficas, visto que é um momento em que os estudantes são autores do processo de ensino e aprendizagem, elencando temáticas dos seus interesses.

O projeto em questão possui três etapas para sua execução e organização, sendo elas: 1) Curso de formação de professores para a Feira de Ciências; 2) Feiras de Ciências nas escolas; e 3) Feira de Ciências Municipal. Todas as etapas estão articuladas, visto que seu desenvolvimento depende, principalmente, do curso de formação para professores. A primeira etapa constitui-se em um curso de extensão, ofertado para os professores da Educação Básica do município de Rio Grande/RS, interessados em organizar Feiras de Ciências nas suas escolas. A finalidade desse curso é fazer com que os professores entendam o processo de organização e realização de uma Feira de Ciências como um projeto investigativo e interdisciplinar, o qual é realizado com o estudante ao longo de um certo tempo, não somente como algo pronto e acabado. Assim, essa Feira de Ciências se torna espaço que possibilita e promova a construção do conhecimento científico pela pesquisa.

No curso, são problematizados alguns tópicos que contribuem para o entendimento das Feiras de Ciências, instigando o professor inscrito a buscar mais informações e o acompanhando no desenvolvimento das Feiras de Ciências nas escolas. $\mathrm{O}$ tópico inicial do curso é referente à "Estrutura da Feira de Ciências" que tem por finalidade contextualizar as etapas do projeto para os participantes, assim como suscitar reflexões sobre a realização de Feiras/Mostras de Ciências no contexto escolar. A temática posterior "Projetos Investigativos e Experimentação" apresenta o desafio do participante para teorizar e para indagar temas relacionados ao desenvolvimento de projetos de investigação no contexto da escola. O terceiro tópico "Tecnologias e Cultura Digital" problematiza como as tecnologias e cultura digital surgem em um curso para a Feira de Ciências, no sentido de entendermos que o processo de ensinar e de aprender pode ser realizado por meio da cultura digital dos estudantes e de seu contexto. Na temática 
DOI: $10.12957 / \mathrm{e}-\mathrm{mosaicos} .2021 .49821$

"Mulheres na Ciência", a discussão é voltada para a inserção das mulheres na Ciência, especificamente, da inserção de meninas nas Feiras de Ciências nas escolas.

Outra temática que faz parte do curso de formação é a de "Práticas Interdisciplinares na Feira de Ciências". Nessa temática, as questões interdisciplinares são discutidas com o professor, de modo a fazê-lo refletir sobre a importância na busca de parcerias na organização e no desenvolvimento de Feiras de Ciências e passos para um projeto ser considerado interdisciplinar. Um dos pilares teóricos que sustentam o projeto de extensão é a interdisciplinaridade, por entendermos que a mesma vai além de somente uma prática, mas enquanto forma de ser e pensar dos professores.

Assim, os professores que participam das atividades ofertadas no referido curso credenciam sua escola a participar da Feira de Ciências municipal. Com isso, a segunda etapa do projeto se caracteriza por um momento de retornar as ações das Feiras de Ciências nas escolas, ou seja, período de colocar em prática a teoria discutida no curso de formação. Dessa forma, os professores que participaram do curso de formação realizam, durante um período, minifeiras de Ciências em suas escolas e ao final selecionam grupos de alunos que participam, posteriormente, da Feira de Ciências Municipal ( $3^{a}$ etapa). Nessa última etapa, temos a realização da Feira de Ciências Municipal com todos os trabalhos selecionados na segunda etapa pelas escolas participantes. Os trabalhos que foram apresentados na terceira edição do projeto, que ocorreu no ano de 2019, farão parte da análise das informações, visto que os resumos enviados foram publicados em um livro de registros da terceira edição do projeto. Desse modo, significamos como as controvérsias sociocientíficas emergem em trabalhos apresentados em Feiras de Ciências, por estudantes da Educação Básica, e como o processo formativo interdisciplinar dos professores pode potencializar essas questões.

\section{ANÁlise dos Resumos: 0 QUe emerge no espaço não formal da Feira de CiênCias?}

No presente trabalho, analisamos os resumos publicados no livro Registros e Relatos 2019 - III Feira de Ciências: Integrando Saberes no Cordão Litorâneo dos trabalhos apresentados. Em cada resumo, buscamos pelas controvérsias sociocientíficas que foram o assunto gerador da pesquisa e, em seguida, discutimos os projetos quanto à interdisciplinaridade. Foram 21 trabalhos que participaram desta edição, sendo 17 vinculados às séries finais do Ensino Fundamental e quatro (4) do Ensino Médio. Os estudantes, em conjunto com professores orientadores, deveriam elaborar um resumo, explicando a metodologia, análise das informações, resultados, ou seja, o processo de desenvolvimento do projeto elaborado a ser apresentado.

Dentre os 21 resumos analisados, compreendemos que 11 apresentam uma CSC como tema gerador, levando-nos a observar como as controvérsias sociocientíficas se encontram presentes em nosso dia a dia, mesmo não sendo frequentemente discutidas 
DOI: $10.12957 / \mathrm{e}-\mathrm{mosaicos} .2021 .49821$

em salas de aula e diferentes ambientes de estudo. Para a análise dos resumos, assumimos alguns critérios, para considerar como CSC, de acordo com Duso e Hoffmann $(2013$, p. 71)

(i) controvérsias que surgem dos impactos sociais de inovações científicotecnológicas que dividem tanto a comunidade científica, como a sociedade em geral; (ii) que permitam discussão entre duas, ou mais partes envolvidas sobre determinada controvérsia, na qual estão em jogo suas crenças e argumentações; (iii) se perante a controvérsia abordada, as pessoas possam se encontrar divididas, envolvendo juízos de valor que impossibilitam a sua resolução apenas através da análise das evidências ou da experiência.

No Quadro 1, indicamos os códigos que assumimos para futura discussão dos resultados, títulos dos resumos, as temáticas que se mostraram presentes em relação às CSC e às categorias emergentes, a partir da análise documental realizada.

Quadro 1: Códigos, títulos dos resumos, temáticas das CSC e categorias emergentes

\begin{tabular}{|c|c|c|c|c|}
\hline Código & Título do Resumo & $\begin{array}{l}\text { Temática da } \\
\text { CSC }\end{array}$ & $\begin{array}{l}\text { Categorias } \\
\text { iniciais }\end{array}$ & Categoria final \\
\hline $\mathrm{R} 1$ & Labirinto Elétrico & \multirow{3}{*}{$\begin{array}{l}\text { Comportamento } \\
\text { humano e a } \\
\text { convivência }\end{array}$} & \multirow{3}{*}{$\begin{array}{c}\text { CSC e o } \\
\text { comportamento } \\
\text { humano: Feira de } \\
\text { Ciências } \\
\text { possibilitando } \\
\text { interações e } \\
\text { reflexões }\end{array}$} & \multirow{8}{*}{$\begin{array}{l}\text { Feira de Ciências: } \\
\text { espaço interdisciplinar } \\
\text { de debate de } \\
\text { controvérsias } \\
\text { sociocientíficas, de } \\
\text { interação e } \\
\text { de auto-eco-formação }\end{array}$} \\
\hline R2 & $\begin{array}{l}\text { Labirinto Elétrico e um } \\
\text { aspirador de pó de } \\
\text { garrafa PET }\end{array}$ & & & \\
\hline R3 & Find a help & & & \\
\hline R4 & Painel Solar Acessível & \multirow{3}{*}{$\begin{array}{l}\text { Produção de } \\
\text { energia } \\
\text { sustentável }\end{array}$} & \multirow{5}{*}{$\begin{array}{c}\text { CSC e o Meio } \\
\text { ambiente: } \\
\text { Desenvolvimento } \\
\text { de tecnologias } \\
\text { com as Feiras de } \\
\text { Ciências }\end{array}$} & \\
\hline R5 & Energia Verde & & & \\
\hline R6 & $\begin{array}{l}\text { Aquecimento da água } \\
\text { por energia solar }\end{array}$ & & & \\
\hline R7 & $\begin{array}{c}\text { Plástico biodegradável } \\
\text { com batatas }\end{array}$ & \multirow[t]{2}{*}{$\begin{array}{l}\text { Reciclagem e } \\
\text { preservação do } \\
\text { meio ambiente }\end{array}$} & & \\
\hline R8 & $\begin{array}{l}\text { Intervenção artística e } \\
\text { fabricação de sabão }\end{array}$ & & & \\
\hline
\end{tabular}


DOI: $10.12957 /$ e-mosaicos.2021.49821

\begin{tabular}{|c|c|c|l|l|}
\hline R9 & Sacola Ecológica & \multirow{2}{*}{} & \\
\cline { 1 - 2 } R10 & $\begin{array}{c}\text { Agrotóxicos } \mathrm{x} \\
\text { agricultura orgânica } \\
\text { familiar }\end{array}$ & $\begin{array}{c}\text { Uso de } \\
\text { agrotóxicos ou } \\
\text { inseticidas }\end{array}$ & & \\
\cline { 1 - 2 } R11 & $\begin{array}{c}\text { Citrocix - inseticida } \\
\text { orgânico }\end{array}$ & & \\
\hline
\end{tabular}

Fonte: Elaborado pelos autores, 2020.

Dessa forma, no Quadro 1, sistematizamos quais são os resumos, que por meio da leitura, apresentam uma discussão que possibilita a inserção das CSC. As categorias emergentes, iniciais e final, são referentes às temáticas dos resumos escritos e que percebemos suas relações, a partir da leitura realizada dos mesmos.

A categoria inicial "CSC e o comportamento humano: Feira de Ciências, possibilitando interações e reflexões" está relacionada aos resumos que tinham por finalidade discutir temas voltados ao comportamento do ser humano em atividades e momentos específicos e até mesmo problemas psicológicos, como depressão e ansiedade, que afetam muitas pessoas em todo o mundo. Já a categoria inicial "CSC e o Meio ambiente: Desenvolvimento de tecnologias com as Feiras de Ciências" há resumos que dissertam sobre a geração de energia com materiais de baixo custo, assim como outros que discutem a diminuição da poluição pela produção de alguns materiais.

Com a análise documental realizada, apresentamos no tópico a seguir a discussão dos resultados que emergiram por meio das categorias iniciais, mas que estão relacionadas através da categoria final "Feira de Ciências: espaço interdisciplinar de debate de controvérsias sociocientíficas, de interação e de auto-eco-formação". Salientamos que a finalidade deste artigo não é problematizar os temas que emergem nos resumos, mas as questões pedagógicas e formativas, mostrando como o espaço não formal de uma Feira de Ciências pode ser potencial de CSC e como a interdisciplinaridade faz parte desses trabalhos.

\section{Feira de CiÊnCIAS: Espaço INTERdisciplinar de debate de CONTROvérsias SOCIOCIENTÍFICAS, DE INTERAÇÃO E DE AUTO-ECO-FORMAÇÃO}

Ao analisarmos os resumos publicados sobre os trabalhos apresentados no projeto de extensão Feira de Ciências: Integrando Saberes no Cordão Litorâneo, percebemos que as Feiras de Ciências podem ser um espaço de proposição e debate de temas interdisciplinares, referentes aos temas sociocientíficos controversos, ou seja, desde questões sociais e psicológicas que afetam o ser humano, até mesmo temas ambientais e 
DOI: $10.12957 / \mathrm{e}-\mathrm{mosaicos} .2021 .49821$

econômicos, que influenciam o ambiente em que vivemos. Argumentamos que a Feira de Ciências, por meio da análise realizada, mostra que a discussão desses temas científicos e tecnológicos promovem a interação entre sujeitos de diferentes níveis acadêmicos e sociais e que faz com que o sujeito se perceba como efeito e causa das suas ações no ambiente que habita, isto é, um processo de auto-eco-formação.

Ressaltamos que os trabalhos foram desenvolvidos por estudantes da Educação Básica e, por isso, mostram uma necessidade de refletir através de atividades que ofereçam diversão, apoio sentimental ou psicológico aos seus colegas, professores e a comunidade em geral, de repensarmos sobre o meio ambiente, Por meio de reciclagem, uso de agrotóxicos ou da produção de energia renovável. Nessa perspectiva, a Feira de Ciências torna-se um espaço que possibilita ao estudante se tornar mais ativo no processo de ensino e aprendizagem, mas além disso, crítico e consciente das suas ações, fator esse que faz parte da questão das CSC na sala de aula. Como afirmam Ramos e Silva (2007, p. 7), as CSC no ensino de ciências ou outras áreas envolve uma "[...] perspectiva de pensar em objetivos educacionais mais amplos que apreensão de conteúdos científicos, como a capacitação dos estudantes para tomadas de decisões em suas vidas cotidianas em questões e situações que envolvam ciência e tecnologia".

Além disso, Borba (1996) apud Mancuso e Leite Filho (2006, p. 23) corrobora sobre a formação ampla que a Feira de Ciências promove nos estudantes que se envolvem com a mesma.

A feira desenvolve no aluno a ação democrática de participação coletiva. Permite a troca de experiências, libera o aluno para um pensar criativo em que a sua capacidade de comunicação é exercitada. Consequentemente, após atuar em uma feira de ciências, nosso aluno retornará à sala de aula com maior capacidade de decisão em relação aos problemas do nosso cotidiano. (BORBA, 1996, p. 43 apud MANCUSO e LEITE FILHO, 2006, p. 23).

Sendo assim, essa capacidade de tomada de decisões é emergente na Educação Básica como forma de promover a alfabetização científica dos estudantes. De acordo com Chassot (2011, p. 55) "[...] a nossa responsabilidade no ensinar Ciência é procurar que nossos alunos e alunas se transformem, com o ensino que fazemos, em homens e mulheres mais críticos". Percebemos essa vontade de compreender alguns fatos que permeiam o cotidiano dos estudantes, na escrita dos resumos dos trabalhos apresentados, como em R2 em que "o objetivo do nosso trabalho é ter uma alternativa de diversão para as pessoas, sendo mais específico, os jovens que hoje em dia só ficam alienados na internet, então o Labirinto Elétrico possibilita esta alternativa [...]". O resumo R1 também apresenta essa busca pelo entendimento de questões sociais. 
DOI: $10.12957 /$ e-mosaicos.2021.49821

Esta ideia surgiu por meio de pesquisas para saber o porquê muitos alunos ficam em seus grupos sociais e não socializam com os demais alunos da escola; então veio a brilhante ideia de fazer um labirinto elétrico para influenciar os alunos a saírem do celular e fazer novas amizades brincando; não podemos esquecer dos professores que podem desafiar seus colegas de trabalho e até alunos. (R1)

O resumo R3 traz uma outra preocupação dos estudantes em relação a problemas que toda a sociedade tem vivenciado, e os mesmos nem possuem formação específica para lidar com certas situações.

Surgiu então a ideia da criação de uma plataforma online, muito objetiva e específica, para ajudar boa parte da sociedade que tem problemas psicológicos comuns atualmente, como a depressão e a ansiedade. Podemos observar que na sociedade atual, problemas como estes acabam afetando seriamente a desenvoltura social de uma pessoa, e muitas vezes não percebemos o quão importante é sabermos sobre quem passa por isso, então, o nosso site Find a Help foi elaborado para ajudar aos que passam por esses problemas diariamente e não tem com quem contar e não sabem exatamente como lidar com este conflito. (R3)

Significamos que a Feira de Ciências possibilita ao estudante se posicionar enquanto pesquisador, buscar alternativas para um problema em questão, elaborar hipóteses e tomar decisões, pontos esses que a Base Nacional Comum Curricular (BNCC) também prioriza dentro do desenvolvimento de competências gerais da Educação Básica. Uma das competências explicita que deve ser dado ênfase no argumento "[...] com base em fatos, dados e informações confiáveis, para formular, negociar e defender ideias, pontos de vista e decisões comuns que respeitem e promovam os direitos humanos [...]", e ressalta outros fatores que emergiram nos trabalhos apresentados pelos alunos como 0 estímulo da "[...] consciência socioambiental e o consumo responsável em âmbito local, regional e global, com posicionamento ético em relação ao cuidado de si mesmo, dos outros e do planeta" (BRASIL, 2016, p. 9).

Essa consciência socioambiental faz parte dos resumos que elencaram temas como a produção de energia sustentável ou preservação do meio ambiente, em que os estudantes tiveram como objetivo, por exemplo, "[...] apresentar o que já temos, como a luz solar sem ferir a natureza, assim poderão facilitar a vida de pessoas com baixa renda, pois para construir um painel solar não é preciso coisas tão "extraordinárias" (R4); "[...] a fabricação artesanal e com recursos renováveis de um substituto ao plástico que deixa 
DOI: $10.12957 / \mathrm{e}-\mathrm{mosaicos} .2021 .49821$

rastros tão desagradáveis ao ambiente e inclusive sua fabricação é altamente poluente" (R7), ou até mesmo "[...] mostrar a utilidade da química em nossa vida além de como podemos agir a favor da natureza com atitudes simples que nos beneficiam também" (R8). Assim como outro trabalho apresentado em que se buscou alternativas sustentáveis para o carregamento do celular.

Com este experimento aprendemos que é possível criar uma nova forma para o carregamento de celulares que não a convencional rede elétrica (que custa caro e utiliza recursos não renováveis para sua obtenção) pela transformação da energia mecânica obtida ao pedalar a bicicleta, que além de não poluente, contribui de forma positiva com o bom funcionamento do nosso corpo, pois realizamos uma atividade física. (R5)

Com isso, percebemos com os resumos dos trabalhos que os sujeitos se auto-ecoorganizam no movimento das Feiras de Ciências, visto que, na auto-eco-organização, temos autonomia e individualidade do sujeito que são dependentes do meio ambiente e das trocas externas realizadas, sendo assim, uma autonomia dependente (MORIN, 2012; 2015). Com essa perspectiva do pensamento complexo, compreendemos que a formação desses estudantes é concebida pela produção e organização de si, mas também pelas interações com o ecossistema, relações essas que foram emergentes nas temáticas dos trabalhos. Nesse processo de auto-eco-formação dos sujeitos, as interações se tornam imprescindíveis, visto que essas que geram um ciclo recursivo de organização do sistema. De acordo com Morin (2016, p. 72) "[...] as interações são ações recíprocas que modificam o comportamento ou a natureza dos elementos, corpos, objetos, fenômenos em presença ou em influência" e, além disso, reforça que "[...] para que haja organização, são necessárias interações: para que haja interações é preciso encontros, para que haja encontro é preciso desordem (agitação, turbulência)" (ibidem).

Sendo assim, nesse movimento formativo e de interações da Feira de Ciências, compreendemos que ambos, sujeito e objeto (o que emergiu na e da Feira de Ciências), transformam-se e aperfeiçoam-se. Assim, considerando a interdisciplinaridade como um processo de interação recursivo, assumimos que

[...] propõe uma orientação para o estabelecimento da esquecida síntese dos conhecimentos, não apenas pela integração de conhecimentos produzidos nos vários campos de estudo, de modo a ver a realidade globalmente, mas sobretudo, pela associação dialética entre dimensões polares, como, por exemplo, teoria e prática, ação e reflexão, generalização e especialização, ensino e avaliação, meios e fins, conteúdo e processo, indivíduo e sociedade etc. (LÜCK, 2013, p. 37). 
DOI: $10.12957 / \mathrm{e}-\mathrm{mosaicos} .2021 .49821$

Ao olharmos para os resumos no viés da interdisciplinaridade somente como integração de conteúdos, chegamos à conclusão de que a mesma não fica expressa nas suas escritas, pois apenas seis resumos trazem uma abordagem interdisciplinar, sendo eles: Painel Solar Acessível, Plástico Biodegradável com Batatas, Aquecimento da água por energia solar, Agrotóxicos X agricultura orgânica familiar, Sacola Ecológica e Citrocix inseticida orgânico. No entanto, ao fazer essa análise restrita emerge um ponto referente à formação inicial dos professores das escolas, pois muitos trabalhos articulavam a temática proposta com os conteúdos das disciplinas ministradas por esses docentes. Assim, ressaltamos que a interdisciplinaridade é um tema de difícil prática e apresenta suas resistências. "Em todos os professores portadores de uma atitude interdisciplinar, encontramos a marca de resistência que os impele a lutar contra a acomodação, embora em vários momentos pensem em desistir da luta" (FAZENDA, 2012, p. 31).

No entanto, a interdisciplinaridade vai além de somente uma integração de conteúdos escolares, pois uma pesquisa interdisciplinar desenvolve "[...] uma formação científica e social, com a qual se evidencia o caráter humano" (FAZENDA, TAVARES e GODOY, 2015, p. 16). Ressaltamos, nesse sentido, alguns fragmentos dos resumos que mostram essas questões: "Aprendemos que ciência pode ser feita de várias maneiras e, uma delas é quando usamos de empatia para proporcionar ajuda aos que precisam" (R3); "[...] aprendemos e nos convencemos que os experimentos servem para reflexão e possíveis alternativas para um futuro com atitudes mais próximas do sustentável. Ciência também é reflexão!" (R7).

Além disso, aprendemos e nos convencemos que as pesquisas servem também para a prática e mudança de atitudes, que existem pessoas que dedicam suas vidas para uma possível melhor qualidade de vida. E, para chegar até este nível às vezes temos alguns tropeços: cortes de verbas, entre outros. Descobertas, acertos, erros, tentativas e dúvidas: tudo em prol da Ciência! (R10)

Nesse processo de auto-eco-formação desses estudantes, percebemos, ainda ,em seus resumos uma atitude de pesquisadores que se faz necessária na resolução de controvérsias sociocientíficas. Os estudantes relatam que "Aprendemos e nos convencemos que nem todo o experimento dá certo, o que resulta em novas hipóteses e novas experimentações, e isto sim, é fazer Ciência. E que nem sempre precisamos de um laboratório (nossa escola não possui) para realizar nossas atividades!" (R5) e "[...] aprendemos e nos convencemos que quando os experimentos não resultam no que esperávamos, não significa um fracasso, às vezes são novas descobertas através do erro, novos questionamentos e tentativas, e isto é Ciência que ultrapassa os muros da escola!" (R6). Com esses entendimentos, Duso e Hoffmann (2013, p. 69) ressaltam que a "[...] 
DOI: $10.12957 / \mathrm{e}-\mathrm{mosaicos} .2021 .49821$

discussão das controvérsias sociocientíficas pode motivar os estudantes a expressar suas opiniões, saber argumentar e tomar decisões bem fundamentadas no que diz respeito ao desenvolvimento científico e tecnológico e suas implicações para a sociedade".

Significamos que a organização e desenvolvimento das Feiras de Ciências nas escolas de Educação Básica são lugares de potencial discussão de temas sociocientíficos controversos, assim como de propiciar a pesquisa investigativa e interdisciplinar pelos estudantes. Com isso, argumentamos que o espaço da Feira de Ciências promove a autoeco-formação dos estudantes, por meio da interação entre os pares, com os professores e o meio ambiente.

\section{Considerações Finais}

Compreendemos com essa investigação como o espaço não formal de uma Feira de Ciências possibilita a emergência de temáticas voltadas às controvérsias sociocientíficas, na perspectiva interdisciplinar. Expressamos com a análise realizada que as Feiras de Ciências são espaços interdisciplinares de conhecimento e de pesquisa, que promovem o debate de controvérsias sociocientíficas, a interação e a auto-eco-formação dos estudantes envolvidos.

Na Fig. 1 descrevemos as emergências da pesquisa realizada, explicitando como as controvérsias sociocientíficas podem fazer parte do espaço não-formal de uma Feira de Ciências, na perspectiva interdisciplinar.

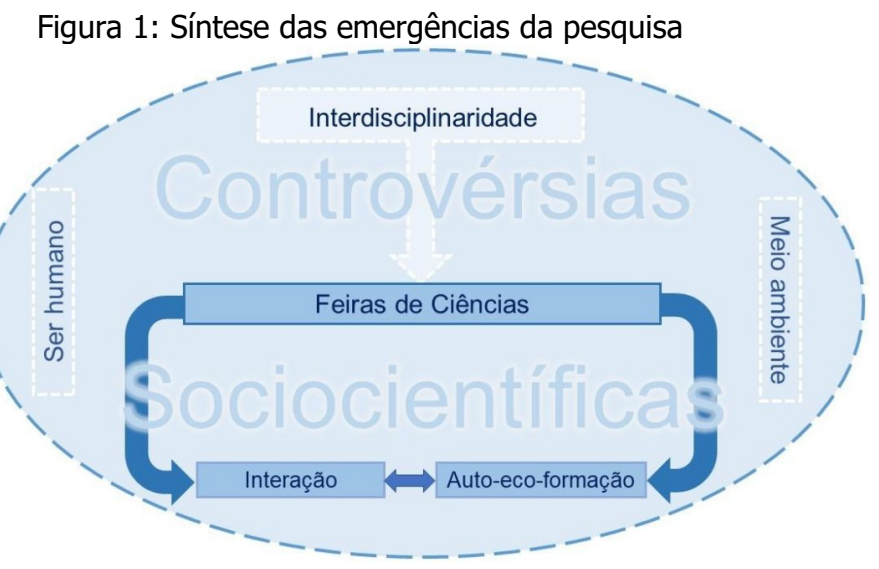

Fonte: Elaborado pelos autores, 2020.

A Fig. 1 contempla que os estudantes vivenciam a discussão de temas controversos sociais e científicos no contexto da escola, percebendo enquanto ser humano que fazem parte e influenciam o meio onde vivem, de forma que nas Feiras de Ciências desenvolvem através das pesquisas, formas de preservar e aperfeiçoar esse meio. No entanto, esses 
DOI: $10.12957 /$ e-mosaicos.2021.49821

fatores são influenciados pelo processo de interação que ocorre nesse espaço, o qual possibilita a auto-eco-formação dos sujeitos envolvidos.

Dessa forma, argumentamos que a inserção e a discussão das CSC em sala de aula da Educação Básica promove reflexão, argumentação e pensamento crítico dos estudantes. Além disso, o debate de CSC por meio de trabalhos apresentados no espaço não formal de uma Feira de Ciências interdisciplinar será gerador de interação e da autoeco-formação dos envolvidos.

\section{REFERÊNCIAS}

BICUDO, M. A. V. A pesquisa interdisciplinar: uma possibilidade de construção do trabalho científico/acadêmico. Educação Matemática Pesquisa, v. 10, n. 1, pp. 137-150, 2008. Disponível em: https://revistas.pucsp.br/emp/article/view/1647/1064. Acesso em: 4 mai. 2019.

BRASIL. Base Nacional Comum Curricular. Brasília: MEC, 2016. Disponível em: http://basenacionalcomum.mec.gov.br/images/BNC C_20dez_site.pdf. Acesso em: 5 mai. 2018.

CHASSOT, A. Alfabetização científica: questões e desafios para a educação. 5 ed. rev. Ijuí: UNIJUÍ: 2011.

DUSO, L.; HOFFMANN, M. B. A discussão das controvérsias sociocientíficas na pesquisa em educação em ciências: uma revisão narrativa a partir de periódicos no Brasil. Ensino de Ciências e Tecnologia em Revista, v. 3, n. 2, jul./dez, pp. 66-85, 2013. Disponível em: http://srvapp2s.urisan.tche.br/seer/index.php/encitec/article/view/1125/528. Acesso em: 15 jan. 2020.

FAZENDA, I. C. A.; TAVARES, D. E.; GODOY, H. P. Interdisciplinaridade na pesquisa científica. São Paulo: Papirus, 2015.

FAZENDA, I. C. A. Interdisciplinaridade: história, teoria e pesquisa. $18^{a}$ ed. Campinas: Papirus, 2012.

FAZENDA, I. C. A. Interdisciplinaridade: qual o sentido? 2a ed. São Paulo: Paulus, 2006.

GALEFFI, D. A. O rigor nas pesquisas qualitativas: uma abordagem fenomenológica em chave transdisciplinar. In: MACEDO, R. S.; GALEFFI, D. A.; PIMENTEL, A. Um rigor outro 
DOI: $10.12957 / \mathrm{e}-\mathrm{mosaicos} .2021 .49821$

sobre a questão da qualidade na pesquisa qualitativa: educação e ciências antropossociais. Salvador: EDUFBA, 2009, pp. 13-73.

GALVÃO, C.; REIS, P.; FREIRE, S. A discussão de controvérsias sociocientíficas na formação de professores. Ciência \& Educação, v. 17, n. 3, p. 505-522, 2011. Disponível em: http://www.scielo.br/pdf/ciedu/v17n3/a01v17n3.pdf. Acesso em: 8 fev. 2020.

KRIPKA, R. M. L.; SCHELLER, M.; BONOTTO, D. de L. Pesquisa Documental: considerações sobre conceitos e características na Pesquisa Qualitativa. In: Congresso Ibero-Americano em Investigação Qualitativa, 2015, Aracaju. Anais do Congresso. Aracaju: Pkp, 2015. v. 6, p. 243247.2 Disponível em: https://proceedings.ciaiq.org/index.php/ciaiq2015/article/view/252/248. Acesso em: 16 mar. 2020.

LÜCK, H. Pedagogia Interdisciplinar: Fundamentos teóricos-metodológicos. $18^{\mathrm{a}}$ ed. Petrópolis: Vozes, 2013.

MANCUSO, R.; LEITE FILHO, I. Feira de Ciências no Brasil: uma trajetória de quatro décadas. In: Programa Nacional de Apoio às Feiras de Ciências da Educação Básica Fenaceb. Brasília: Ministério da Educação, Secretaria de Educação Básica. 2006.

MORIN, E. O método 1: a natureza da natureza. 3 ed. Porto Alegre: Sulina, 2016.

MORIN, E. Introdução ao pensamento complexo. 5 ed. Porto Alegre: Sulina, 2015.

MORIN, E. O método 5: a humanidade da humanidade. 5 ed. Porto Alegre: Sulina, 2012.

RAMOS, M. B.; SILVA, H. C da. Controvérsias científicas em sala de aula: uma revisão bibliográfica contextualizada na área de ensino de ciências e nos estudos sociológicos da Ciência \& Tecnologia. VI Encontro Nacional de Pesquisa em Educação em Ciências. Anais do VI ENPEC. 2007.

REIS, P. Controvérsias sóciocientíficas: discutir ou não discutir?: Percursos de aprendizagem na disciplina de ciências da terra e da vida. Tese de doutorado. Faculdade de Ciências. Departamento de Educação. Universidade de Lisboa. 2004. Disponível em: https://repositorio.ul.pt/bitstream/10451/3109/1/ulsd046398_td_Pedro_Reis.pdf. Acesso em: 2 mar. 2020.

REIS, P. O "admirável mundo novo" em discussão. Lisboa: Ministério da Educação, Instituto de Inovação Educacional, 2003. 
DOI: $10.12957 / \mathrm{e}-\mathrm{mosaicos} .2021 .49821$

SÁ-SILVA, J. R.; ALMEIDA, C. D.; GUINDANI, J. F. Pesquisa documental: pistas teóricas e metodológicas. Revista Brasileira de História \& Ciências Sociais, n. 1, p. 1-15, jul., 2009. Disponível em: https://periodicos.furg.br/rbhcs/article/view/10351/pdf. Acesso em 17 nov. 2019.

Recebido em 02 de abril de 2020

Aceito em 15 de março de 2021

A e-Mosaicos Revista Multidisciplinar de Ensino, Pesquisa, Extensão e Cultura do Instituto de Aplicação Fernando Rodrigues da Silveira (CAp-UERJ) está disponibilizada sob uma Licença Creative Commons - Atribuição - NãoComercial 4.0 Internacional.

Os direitos autorais de todos os trabalhos publicados na revista pertencem ao(s) seu(s) autor(es) e coautor(es), com o direito de primeira publicação cedido à e-Mosaicos.

Os artigos publicados são de acesso público, de uso gratuito, com atribuição de autoria obrigatória, para aplicações de finalidade educacional e não-comercial, de acordo com o modelo de licenciamento Creative Commons adotado pela revista. 